\title{
A Dificuldade de Encontrar Palavras: inferências a partir da análise qualitativa de entrevistas com sujeitos idosos
}

\author{
Larissa Picinato Mazuchelli \\ Universidade Estadual de Campinas (UNICAMP), Campinas, São Paulo, Brasil \\ lpmazuchelli@gmail.com
}

DOI: http://dx.doi.org/10.21165/el.v46i2.1660

\begin{abstract}
Resumo
Os estudos sobre envelhecimento vêm aumentando no Brasil e no mundo, considerando-se o que muitos têm chamado de "revolução da longevidade" (HÉBERT, 2015; MINAYO; GUALHANO, 2014). Contudo, apesar desses avanços, há escassez de investigações linguísticas da produção do discurso do idoso no Brasil. Nesse quadro, nosso trabalho procura mostrar como estudos fundamentados em uma perspectiva sócio-histórico-cultural podem contribuir para melhor compreendermos a linguagem no envelhecimento. Este trabalho visa refletir, mais especificamente, sobre o fenômeno da Dificuldade para Encontrar Palavras - uma das principais queixas dos idosos segundo Burke e Shafto (2004) - no contexto de envelhecimento "normal" (sem alteração de linguagem). Nossa reflexão fundamenta-se na Neurolinguística EnunciativoDiscursiva e mobiliza os trabalhos de Vygotsky (2010), Luria (1990, 1991), Damico et al. (1999) e Bakhtin (2003), dentre outros importantes autores.

Palavras-chave: neurolinguística; linguagem e envelhecimento; dificuldade para encontrar palavras.

\section{Word Finding Difficulties: inferences from a qualitative analysis of interviews with aged individuals}

\begin{abstract}
Studies on aging have been increasing in Brazil and around the world, considering what many researchers have called as "the revolution of longevity" (HÉBERT, 2015; MINAYO; GUALHANO, 2014). However, despite these advances, there have been only few linguistic investigations regarding elderly speech production in Brazil. In this context, our work is an attempt to evidence how studies based on a socio-historical-cultural perspective can contribute to a better understanding of language in aging. This work aims to reflect more specifically on the phenomenon Word Finding Difficulties - one of the main complaints of the elderly people, according to Burke and Shafto (2004) - in the "normal" aging context (without language alteration). Our reflection is based on the Enunciative-Discoursive approach to Neurolinguistics and mobilizes the works of Vygotsky (2010), Luria (1990, 1991), Damico et al. (1999) and Bakhtin (2003), among other important authors.
\end{abstract}

Keywords: neurolinguistics; language and aging; Word Finding Difficulties. 


\section{Introdução}

Um personagem, chamado Leitor, compra uma edição de "Se um viajante numa noite de inverno", de Italo Calvino. Durante sua leitura, percebe que se trata de uma versão "defeituosa". Volta, então, à livraria e ao começar a ler o novo volume, agora aparentemente sem falhas, descobre que este em nada se parece com o romance que havia lido. O Leitor passa, então, a uma incessante busca pela continuação do primeiro romance, envolvendo-se em um verdadeiro labirinto de histórias, personagens e lugares. Nessa busca, depois de já ter iniciado a leitura de outros dois romances, sem que pudesse concluí-los, pois as histórias são repentinamente interrompidas, encontra o senhor Cavadagna, o editor, com quem estabelece o diálogo seguinte (CALVINO, 2011, p. 102, grifo nosso):

- O que sei lhe direi de boa vontade - responde o editor. Escute só. Tudo começou quando se apresentou aqui na editora um jovem que afirmava ser tradutor de... Como é que se diz?...

- Polonês?

- Não, não de polonês! Uma língua difícil, que é conhecida por poucos.

- Cimério?

- Não, não, mais para lá, como se diz mesmo? Ele se fazia passar por um poliglota extraordinário, não havia idioma que não conhecesse, inclusive o címbrico, é o címbrico. Trouxe um livro escrito nessa língua, um romance volumoso, denso, como se chamava? O Viajante.... Não: Viajante é daquele outro, o Fora do povoado.

- De Tatius Bazakbal?

- Não, Bazakbal não, desse era o Despenhadeiro. Deixe-me ver, do...

- Ahiti?

- Bravo! Exatamente, Ukko Ahiti.

Esse diálogo, em que o senhor Cavadagna, com a ajuda do Leitor, busca lembrar o nome do tradutor - informação fundamental para explicar/narrar a história dos livros inacabados - nos remete a algumas particularidades sobre a Dificuldade de Encontrar Palavras (doravante $\mathrm{WFD}^{1}$ ) e sua relação com a linguagem no chamado envelhecimento normal $^{2}$, tema deste artigo ${ }^{3}$. É de nosso interesse retomar e refletir, portanto, ao longo deste texto, as seguintes características: (i) o WFD faz parte do funcionamento normal da linguagem; (ii) é locus interessante para investigar e compreender as estratégias linguístico-cognitivas utilizadas para alcançar o intuito discursivo (BAKHTIN, 2003); (iii) mostra que a busca pela palavra-alvo é dialógica.

\footnotetext{
${ }^{1}$ Utilizamos a sigla em inglês (WFD - Word Finding Difficulties) uma vez que é usada com maior frequência, inclusive na literatura em português.

${ }^{2}$ Destacamos normal para chamar atenção à discussão entre normalidade e patologia, já que a consideração do que é, ou não, normal decorre, além de aspectos biológicos, de aspectos históricos, culturais e políticos. ${ }^{3}$ Este trabalho insere-se em uma pesquisa de doutorado, em andamento, intitulada: "A linguagem nos processos de envelhecimento normal e patológico na perspectiva da Neurolinguística" em que propomos refletir criticamente acerca: (i) dos discursos sobre envelhecimento que circulam na sociedade, e (ii) da produção linguística (seus contextos pragmático-discursivos) de sujeitos em processo de envelhecimento normal e patológico, residentes e não residentes de uma Instituição de Longa Permanência de Campinas. A pesquisa é financiada pela FAPESP (Processo: 2015/15515-1), a quem agradeço o apoio, e está inserida nos estudos realizados pelo Grupo de Estudos da Linguagem no Envelhecimento e nas Patologias (GELEP - Plataforma CNPq/IEL/UNICAMP), sob coordenação da Profa. Dra. Rosana do Carmo Novaes-Pinto. Pesquisa aprovada pelo Comitê de Ética em Pesquisa da UNICAMP (Processo: 51794415.7.0000.5404).
} 
Para que este objetivo seja alcançado, retomaremos, primeiramente, alguns estudos sobre a relação entre linguagem e envelhecimento. Em seguida, discutiremos como a Neurolinguística de orientação Enunciativo-Discursiva (doravante ND) pode contribuir com os estudos da área e para a compreensão do fenômeno investigado. Finalmente, essa reflexão fundamenta-se na análise qualitativa, de cunho microgenético, de três dados provenientes de enunciados dialógicos de entrevistas semiestruturadas realizadas com dois sujeitos (RM e EM) no primeiro semestre de 2016, em Campinas, interior de São Paulo.

\section{Os Estudos sobre Linguagem e Envelhecimento: breve panorama}

Nesta seção, apresentamos brevemente uma reflexão sobre alguns dos trabalhos de maior relevância sobre linguagem e envelhecimento. Para tanto, nos fundamentamos nos trabalhos de Brandão (2006), Brandão e Parente (2001) e Lourenço e Massi (2011) pela natureza abrangente e pelo caráter histórico de seus trabalhos.

Na revisão de literatura de estudos sobre linguagem e envelhecimento realizados no século passado, Brandão e Parente (2001) mostram que, em um primeiro momento, os estudos sobre linguagem e envelhecimento se interessavam mais por compreender, descrever e explicar as alterações e os déficits decorrentes do envelhecimento. Em um segundo momento, observa-se um aumento do número de pesquisas interessadas por outras questões, mais subjetivas, como bem-estar e qualidade de vida. Esse movimento parece, a nosso ver, acompanhar um processo de mudança dos estudos sobre envelhecimento de um foco nos déficits orgânicos para questões relativas à

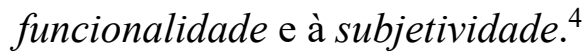

A maior parte dos estudos sobre linguagem e envelhecimento fundamenta-se, como mostra Brandão (2006), em uma divisão entre "produção" e "compreensão" que, através de $\operatorname{modelos}^{5}$, procura descrever e explicar possíveis alterações associadas ao envelhecimento. Como aponta a autora: "Grande parte dos estudos apresenta delineamento experimental, propondo a realização de tarefas de expressão de linguagem que se caracterizam por buscar controlar o contexto comunicativo e determinadas variáveis que podem atuar na produção dos indivíduos" (BRANDÃO, 2006, p. 141). Contudo, o grande foco de pesquisa, segundo a autora, seriam os estudos que se interessaram por questões de "compreensão", em virtude de "uma maior facilidade em se controlar" as condições dos experimentos ${ }^{6}$.

\footnotetext{
${ }^{4}$ Sobre a mudança de foco do corpo para questões mais subjetivas - ainda que observemos o interesse pelo primeiro prevalecer -, sugerimos o texto de Lourenço e Massi (2011).

${ }_{5}^{5}$ Brandão (2006) cita três modelos de processamento que procuram explicar a produção linguística. $\mathrm{O}$ de Van Dijk (2003), de Dell (1986) e Garrett (1975). Segundo o primeiro modelo, a produção do discurso é dividida em duas etapas. Nesse modelo, as etapas poderiam ocorrer "de forma quase paralela e interagir entre si, sendo que o processamento pragmático pode interferir no processamento sintático" (BRANDÃO, 2006, p. 135). O segundo modelo afirma que o processamento linguístico é serial, não havendo interação entre os estágios de (i) conceituação, (ii) formulação e (iii) articulação. Por fim, o modelo de Dell (1986), chamado de paralelo, postula que os diferentes níveis de processamento (semântico, sintático, morfológico e fonológico) formariam, paralelamente, um tipo de representação, agindo simultaneamente.

${ }^{6}$ Apesar de não ser esse o objetivo deste trabalho, acreditamos ser fundamental retomar a discussão feita por Novaes-Pinto (2007) que, baseando-se principalmente nos trabalhos de Luria (1981), afirma "que os complexos processos de produção e compreensão são operações interdependentes e que ambos necessitam do trabalho articulado e solidário de diferentes áreas do cérebro para se desenvolverem. Estudos de casos
} 
Um dos aspectos mais encontrados na literatura sobre "produção" linguística de idosos sem patologias neurológicas, segundo Brandão (2006), é a chamada Verbosidade Fora de Tópico (VFT), caracterizada como "fala aumentada e por mudanças súbitas e repentinas de tópico [...] e exibem uma perda contínua do foco no discurso, realizando diversas mudanças de tópico, o que demonstra falta de coerência no discurso" (BRANDÃO, 2006, p. 143). Ainda segundo a autora, apoiada nos estudos de Arbuckle e Gold (1993): "os resultados demonstram que parte dos idosos produz fala mais prolongada e irrelevante ao assunto, caracterizando verbosidade fora de tópico". De maneira geral, esses autores justificam a VFT ou pela hipótese de um "déficit de inibição" - em que uma parte de idosos saudáveis sofreria um declínio no mecanismo de inibição - ou pela hipótese de "mudança pragmática", segundo a qual "o determinante da mudança de tópicos no discurso dos idosos está no contexto social e na identidade do falante" (BURKE, 1997 apud BRANDÃO, 2006) 7.

Vale a pena notar que, na revisão bibliográfica de Brandão e Parente (2001), o único trabalho de análise linguística de referência, realizado com e sobre falantes do português brasileiro, foi o de Preti (1991), que resulta de uma reflexão fundamentada em um corpus restrito, como atesta a descrição feita por Marcuschi (1991, p. 17 apud PRETI, 1991, grifo nosso), na introdução da obra:

Na pesquisa que desenvolvemos sobre a linguagem de idosos, realizamos 25 gravações, a maioria das quais em torno de 15 a 30 minutos de duração, com falantes que vão de 80 a 101 anos de idade. Nesta obra [Preti, 1991], no entanto, a teoria está documentada, na maioria dos casos, com apenas uma das gravações. Trata-se do diálogo no. 396-D2 que também pertence ao Projeto de estudo da norma linguística urbana culta de São Paulo (Projeto NURC/SP), com 75 minutos de duração, o qual, além de bem mais longo, se revelou qualitativamente superior aos demais inquéritos. [...] No capítulo $\mathrm{V}$, a propósito do problema da sobrevivência na memória de palavras de um discurso realizado há muitas décadas antes, valemo-nos também de outros dois diálogos (um com uma entrevistada de 101 anos).

Os demais trabalhos citados ${ }^{8}$ referem-se a investigações psicométricas realizadas na Europa ou nos Estados Unidos. Enquanto, por um lado, reconhecemos a relevância de tais trabalhos - ainda que questionemos suas escolhas teóricas e metodológicas -, por outro, o predomínio desses trabalhos no Brasil reforça a observação, já feita por Neri (1991), da necessidade de realizarmos estudos sobre envelhecimento no Brasil, tanto em virtude das diferenças culturais e históricas, quanto pelos próprios dados conflitantes dos estudos realizados no exterior.

colocam em cheque a crença de que possam ser comprometidos isoladamente, como postulam os modelos de dupla dissociação" (FUGIWARA; NOVAES-PINTO, 2013, p. 904).

7 De maneira geral, Brandão e Parente (2001) afirmam que os principais trabalhos sobre produção confirmariam a ideia de que, no envelhecimento, há "uma produção de fonemas menos clara". Por outro lado, as autoras também chamam atenção para estudos de aspectos semânticos e lexicais que apontam para uma estabilidade (ou mesmo evolução) desses aspectos no envelhecimento, apesar de "perdas de rapidez e de articulação" e justificam essa característica pela "maior experiência linguística com o decorrer da vida" (BRANDÃO; PARENTE, 2001, p. 39).

${ }^{8}$ Para a revisão bibliográfica, as autoras se baseiam nos trabalhos de Ryan e Laurie (1990), Salthouse (1987) e Stine, Wingfield e Poon (1989), alguns dos principais autores que investigaram aspectos da linguagem no envelhecimento. 
Um dos principais resultados da escassez de trabalhos linguísticos sobre a produção dessa parcela da população é a consideração, por exemplo, de que idosos "não falam coisa com coisa", de que prolixidade é característica dessa parcela da população (como se não houvesse adolescentes e adultos prolixos, por exemplo) ou, como observamos acima, que idosos estão mais sujeitos a uma verbosidade "fora do tópico", portanto, "ineficiente", "irrelevante". Ou seja, características que podem ser associadas a diferentes segmentos etários da população passam a ser marcas de envelhecimento e sintomas de uma patologia (de uma alteração, de um déficit, de um declínio).

Como afirma Preti (1991, p. 28), em virtude do medo de "cometer erros que infrinjam quaisquer modelos aceitos pelos mais jovens", esses sujeitos adotam "uma atitude bem característica de autodesvalorização, subestimando-se, o que constitui um dos estereótipos mais marcantes da própria velhice". Os mitos e estereótipos que caracterizam o discurso sobre o idoso parecem, assim, marcar a fronteira entre o normal e o patológico, uma vez que esta não se baseia em análises linguísticas dos enunciados dos idosos. Trata-se, como aponta Novaes-Pinto (2008, p. 19), de uma constatação sem fundamentação linguística: "o que se percebe é que quando o papel social do idoso se altera com a perda do status social em um determinado momento de sua vida, características de sua linguagem passam a ser também recusadas ou tidas até como sintomas de uma patologia", abrindo caminho para a criação de novas categorias de avaliação - "categorias sem sujeito" (MAZUCHELLI, 2012)".

A esse respeito e como maneira de introduzir uma reflexão linguística crítica acerca da produção linguística no envelhecimento e, mais especificamente, sobre o fenômeno WFD, apresentamos, ainda que longa, uma reflexão belíssima sobre os estereótipos, realizada por Carmelino e Possenti (2015, p. 418-419, grifo nosso):

\begin{abstract}
Nesse sentido, o estereótipo passou a ser considerado, num sentido mais estável, como social, construído e imaginário. Nas palavras de Amossy e Herschberg-Pierrot (2001), trata-se de uma imagem coletiva, simplificada e cristalizada de algo (pessoa, grupo, assunto), que resulta - a partir de um processo que recorta ou categoriza o real - de expectativas, hábitos de julgamento ou generalizações recorrentes na sociedade" [...] Enquanto os autores sustentam que, por um lado, os estereótipos podem assumir um papel de organizador cognitivo, no sentido de que possibilitam a promoção de identificação de grupos e indivíduos, por outro, a categorização simplificada ou generalizada pode provocar uma visão esquemática e deturpada do real, gerando falsas evidências. Como os estereótipos comumente referem ao todo selecionando alguns detalhes, tendem a oferecer uma imagem incompleta (eventualmente, errada), que implica ou provém de uma qualificação ou julgamento.
\end{abstract}

Concordarmos, assim, com os autores, acerca da relevância dos estudos sobre estereótipos e entendemos que, para termos uma imagem mais completa da relação entre linguagem e envelhecimento, precisamos investir em análises linguísticas que incluam em seu referencial teórico e metodológico questões relativas à cultura e à história.

Considerando o exposto até aqui, ressaltamos dois pontos essenciais para os estudos sobre linguagem e envelhecimento e para a investigação do fenômeno: (i) a necessidade de ampliarmos o escopo de análise da linguagem dos idosos, considerando diferentes faixas etárias e as práticas sociais orais letradas, em processos normais e

\footnotetext{
${ }^{9}$ Skliar (2003), refletindo sobre esses aspectos da avaliação na educação, fala em "nomenclaturas sem sujeitos".
} 
patológicos, atentando para os aspectos formais das construções linguísticas e seus contextos pragmático-discursivos; (ii) a necessidade de explorarmos caminhos teóricos e metodológicos que considerem os aspectos linguísticos, culturais, históricos e sociais do Brasil, uma vez que, como afirma Damico et al. (1999, p. 654), baseado em outros autores da área ${ }^{10}$ : "Uma vez que estruturas sociais "macro" ou "globais" surgem e são sustentadas por ações sociais "locais" ou "micro", as micro características da vida social manifestadas nas ações imediatas dos indivíduos - são uma preocupação primordial para os pesquisadores qualitativos".

\section{A Neurolinguística Enunciativo-Discursiva: um percurso teórico e metodológico para os estudos sobre a Dificuldade de Encontrar Palavras}

Procuramos mostrar, na seção anterior, alguns dos principais trabalhos de investigação de pesquisadores que se interessam pela relação entre linguagem e envelhecimento. Aqui, discutimos como a Neurolinguística de orientação enunciativodiscursiva pode contribuir com essa discussão.

Como vimos no trecho do romance de Calvino, uma das características do fenômeno da WFD é que essa dificuldade pode ser observada nas produções de sujeitos com e sem alteração de linguagem. Segundo Burke e Shafto (2004), essa dificuldade é a maior responsável pelas queixas que sujeitos idosos fazem. Nas palavras das autoras ${ }^{11}$ :

Adultos mais velhos relatam que um de seus problemas cognitivos mais irritantes é a inabilidade de produzir uma palavra bem conhecida. Embora pessoas de todas as idades sofram tais falhas para encontrar palavras, esse tipo de erro se torna mais frequente com a idade, e adultos mais velhos relatam que é o problema cognitivo mais afetado pelo envelhecimento. Compreender a natureza e a causa das falhas para encontrar palavras é um objetivo importante para a pesquisa sobre envelhecimento porque essas falhas podem diminuir o sucesso dos idosos na comunicação e enfraquecer a avaliação de sua competência linguística por si e por outros. Essa auto-avaliação negativa promove a retirada da interação social. (BURKE; SHAFTO, 2004, [n.p.], grifo nosso).

O interesse pela investigação desse fenômeno na normalidade nasce do desejo de melhor compreender sua natureza, uma vez que isso pode nos ajudar a entender aspectos da relação entre linguagem e envelhecimento tanto quanto o próprio processo e as estratégias utilizadas pelos sujeitos para lidar com essa dificuldade.

Um dos aspectos teóricos mais relevantes da Neurolinguística enunciativodiscursiva é a relevância dada (tanto na teoria, quanto na prática de avaliação e análise linguística) à relação entre língua(gem), sujeito e cérebro. Partimos da consideração de que o sujeito atua com e sobre a linguagem, esta concebida como "uma atividade humana,

\footnotetext{
${ }^{10}$ No original: "Since 'macro' or 'global' social structures arise and are sustained from 'micro' or 'local' social actions, the micro features of social life - manifested in the immediate actions of the individuals are of primary concern to qualitative researchers (Garfinkel 1967, Goodwin 1981, Heritage 1984).”

${ }^{11}$ Older adults report that one of their most annoying cognitive problems is the inability to produce a wellknown word. Although people of all ages suffer such word-finding failures, this type of error becomes more frequent with age, and older adults report that it is the cognitive problem most affected by aging. Understanding the nature and cause of word-finding failures is an important goal for aging research because these failures may diminish older adults' success in communicating, and weaken the evaluation of their language competence by themselves and others. Such negative self-appraisal promotes withdrawal from social interaction. (BURKE; SHAFTO, 2004, [n.p.]).
} 
lugar de interação e interlocução de sujeitos, indeterminada, incompleta e passível de (re)interpretação, em que tanto o sujeito quanto ela própria se constituem em um movimento dinâmico" (MAZUCHELLI, 2012 apoiada nos trabalhos de FRANCHI, 1975; COUDRY, 1988; GERALDI, 1990).

Coerente com a concepção de sujeito, buscamos em Luria (1991) a concepção de cérebro, por ele caracterizado como um Sistema Funcional Complexo, fortemente influenciado pelas condições externas ao sujeito: sua história, sua cultura, sua relação com o mundo exterior - princípio conhecido na literatura neuropsicológica como organização extracortical (VYGOTSKY apud KOTIK-FRIEDGUT, 2006), também referido por influência epigenética ${ }^{12}$.

Em outras palavras, é a articulação teórico-metodológica desses conceitos de cérebro, língua(gem) e sujeito no curso de desenvolvimento da história do sujeito, que possibilita que a Neurolinguística observe fenômenos relacionados à linguagem e ao envelhecimento, como a WFD, de maneira especial. Nesse sentido, a análise qualitativa revela-se como uma metodologia ideal para essa reflexão, uma vez que, para compreender um fenômeno dessa natureza, precisamos mobilizar um conjunto de práticas sistemáticas e interpretativas "projetadas para buscar respostas a perguntas que enfatizam como ações sociais e experiências sociais são criadas e sustentadas"13 (DAMICO et al., 1999, p. 652, grifo nosso).

É, portanto, o principal foco de investigação da análise qualitativa, como afirma Damico et al. (1999, p. 653, tradução nossa) ${ }^{14}$ : "um interesse pelos mecanismos ou processos pelos quais a ação social é realizada". É disso que fala Vygotsky (2010, p. 396) quando critica "a falha metodológica principal da imensa maioria de investigações do pensamento e da linguagem" que "decompunha essa totalidade nos seus elementos constituintes $[. .$.$] que não contêm propriedades inerentes a essa totalidade". Para ele, é$ fundamental, para a compreensão da relação entre linguagem e pensamento, que:

Procuremos substituir a análise que aplica o método da decomposição em elementos pela análise que desmembra a unidade complexa do pensamento discursivo em unidades várias, entendidas estas como produtos da análise que, à diferença dos elementos, não são momentos primários constituintes em relação a todo o fenômeno estudado mas apenas a alguns dos seus elementos e propriedades concretas, os quais, também diferentemente dos elementos, não perdem as propriedades inerentes à totalidade e são suscetíveis de explicação mas contêm, em sua forma primária e simples, aquelas propriedades do todo em função das quais se empreende a análise. A unidade a que chegamos na análise contém, na forma mais simples, as propriedades inerentes ao pensamento discursivo enquanto unidade (VYGOTSKY, 2010, p. 397-398, grifo nosso).

Segundo Góes (2000, p. 9), a perspectiva defendida por Vygotsky é referida como microgenética por ser "uma forma de construção de dados que requer a atenção a detalhes

\footnotetext{
${ }^{12}$ Luria (1991) afirma que são três os traços que sintetizam a atividade consciente do homem: (i) não está ligada necessariamente a motivos biológicos; (ii) não é determinada diretamente por impressões evidentes, uma vez que o homem é capaz de abstrair a experiência imediata e interpretar de maneira profunda os sinais dessa experiência; e (iii) o conhecimento e as habilidades do homem se formam "por meio da assimilação da experiência de toda a humanidade" (LURIA, 1991, p. 73).

${ }^{13}$ No original, em inglês, "designed to seek answers to questions that stress how social actions and social experiences are created and sustained".

${ }^{14}$ No original, "an interest in the mechanisms or processes by which social action is accomplished".
} 
e o recorte de episódios interativos, sendo o exame orientado para o funcionamento dos sujeitos focais, as relações intersubjetivas e as condições sociais da situação, resultando num relato minucioso dos acontecimentos" ${ }^{15}$. Podemos afirmar, assim, que a análise qualitativa de cunho microgenético se interessa pelos detalhes das ações, pelas interações e pelo cenário social e cultural em que o objeto investigado se encontra.

Acreditamos que essa maneira de olhar e analisar os dados, fundamentada em princípios histórico-culturais, contribui para que revisitemos criticamente os mitos e estereótipos associados ao envelhecimento, como vimos anteriormente.

\section{A Dificuldade de Encontrar Palavras: como é que se diz mesmo?}

Nessa seção, discutimos os dados de entrevistas (com duração média de 30 minutos) com dois sujeitos (RM e EL) em processo de envelhecimento, sem diagnóstico de alterações linguístico-cognitivas, e residentes da região de Campinas a maior parte da vida. Antes, contudo, de iniciarmos a discussão, acreditamos ser essencial explicar que as entrevistas têm como objetivo principal obter dados de produção oral de indivíduos com mais de 60 anos para constituir um banco de dados para futuras análises dessas produções como forma de i) melhor compreender fenômenos linguístico-cognitivos dessa parcela da população e ii) ser uma forma de registro de histórias de vida e de memória. A reflexão que apresentamos, portanto, parte de inferências realizadas a partir da análise desses dados e que, apesar de inicial, mostra indícios de um caminho interessante de investigação sobre a relação entre linguagem e envelhecimento.

O primeiro sujeito deste trabalho é RM, nascida no interior de São Paulo em 1945, tendo mudado para Campinas em 1952. Ao longo da entrevista, RM repetiu algumas vezes como gostaria de ter podido continuar estudando e ter feito ensino superior. RM estudou até os 16 anos, quando terminou o chamado "clássico". Com o falecimento da mãe, ela e as irmãs precisaram deixar os estudos para ajudar com os afazeres domésticos, enquanto os irmãos passaram a trabalhar fora. Atualmente, RM reside sozinha em Campinas, é divorciada e trabalha como voluntária em uma instituição religiosa onde ministra cursos sobre sua religião na própria instituição e em um presídio da região. $\mathrm{Na}$ entrevista, RM mostrou como sua prática diária de estudos, em decorrência das demandas da instituição religiosa, foram essenciais para que se assumisse uma postura autodidata e de contínua aprendizagem.

Dentre os diversos temas sobre os quais conversamos, neste trecho da entrevista, RM conta para a investigadora LM sobre sua relação com seus filhos e netos. No dado 1, apresentamos o momento em que RM explica a condição com que um de seus netos nasceu.

\footnotetext{
${ }^{15}$ A autora compara a análise microgenética a outros tipos de análise que também se inserem no contexto teórico histórico-cultural, por exemplo: os estudos etológicos, com descrições minuciosas de comportamentos, que se interessam pelas formas de relação entre comportamento e condições ambientais; as pesquisas comportamentalistas, em que há análise dos detalhes de estímulos e respostas, etc.; e a abordagem microetnográfica que analisa, a partir da descrição ou reconstrução analítica do cenário e das regras de funcionamento de um grupo cultural da interação social, como microcomportamentos compõem processos organizacionais (GÓES, 2000).
} 
Dado 1. Entrevista com RM em 17/06/2016 - Mielomeningoceli

\begin{tabular}{|c|c|c|}
\hline Sigla & Tempo & Enunciado \\
\hline LM & $99^{\prime} 01$ & me fala um pouco dos seus filhos... a senhora tem três? \\
\hline RM & 9’02 & $\begin{array}{l}\text { então... eu tenho } 3 \text { filhos... gostaria até de ter tido mais ... a a menina mais velha... } \\
\text { tem } 47 \text { acabou de fazer } 47 \ldots \text { a minha filha do meio tem... } 44 \text { e o meu filho vai fazer } \\
\text { agora } 41 \ldots \text { em agosto né... a são criaturas... cada um diferente do outro é claro... } \\
\text { ainda bem... mas são... criaturas... pra mim são maravilhosas... é carinhosos todos } \\
\text { eles... se preocupam muito comigo e eles... e eu ajudo na medida que eu posso } \\
\text { sempre... porque a minha filha do meio tem um filho que nasceu com [9'47] } \\
\text { mielo/ meni/ meningoceli... [9'50] está com } 14 \text { anos... mas desde que nasceu eu } \\
\text { estou sempre juntos... em todas as ocasiões }\end{array}$ \\
\hline LM & 9'58 & o que é? eu não conheço... desculpa \\
\hline RM & $\begin{array}{l}9 ' 59 \\
10 ' 11 \\
10: 29 \\
10: 33 \\
10: 37 \\
10: 44\end{array}$ & $\begin{array}{l}\text { mielomeningoceli a coluna não fechou... então nasce aberta.... e conforme a altura } \\
\text { que nasce aberta.... os problemas são diferentes... o dele... ficou aberta do cóccix... } \\
\text { quando ele nasceu tinha uns } 8 \mathrm{~cm} \text { aberta... é muito pra um bebezinho... mas graças a } \\
\text { Deus ele nasceu no HC em São Paulo e no dia mesmo lá... no outro não me lembro } \\
\text { bem... ele já... tentaram fechar o que foi possível porque enervação né... não é } \\
\text { assim... então ele é para/ cadeirante paralítico da cintura para baixo, então... por } \\
\text { consequência disso tem hidrocefalia... NÉ }\end{array}$ \\
\hline
\end{tabular}

O primeiro aspecto que nos chama atenção nesse episódio é a aparente facilidade e rapidez com que RM traz informações novas e relevantes para o tema discutido. $O$ tema sobre filhos e netos é apresentado por LM aos nove minutos da entrevista. Em menos de um minuto (9'02 até 9'57), RM apresenta seus filhos e fillhas, a idade de cada um deles, chamando atenção para os aniversários de dois deles, traz características de sua relação com eles ("criaturas diferentes", "carinhosos", "se preocupam muito comigo", "eu ajudo na medida que eu posso"), além da condição em que se encontra um de seus netos e de sua idade.

Nesse momento, vale a pena abrirmos um parêntese para explicar a presença de marcas de tempo na transcrição. Como observado nas seções anteriores, a análise qualitativa de cunho microgenético orienta-se para indícios que nos ajudem a compreender um processo. Isso significa, por um lado, observar atentamente os dados em busca das pistas que contribuam para explicar o fenômeno investigado; por outro, esse tipo de investigação demanda (re)pensar a maneira como os dados são lidos (interpretados). Trata-se, assim, de assumir a responsabilidade de adaptar a análise para o que se investiga, como afirma Damico et al. (1999, p. 655, grifo e tradução nossos $)^{16}$ : "A fim de coletar e analisar dados naturais, dinâmicos e complexos, é importante ter flexibilidade para ajustar ambos os métodos de coleta e análise de dados para atender às necessidades da pesquisa em qualquer momento específico".

Foi a análise das entrevistas dos sujeitos que compõem este estudo que nos levou a considerar - para a compreensão dos dados e do fenômeno da WFD - a inserção das marcas de tempo e como essa informação poderia revelar algo importante sobre o processo; a saber: a rapidez com que informações novas e relevantes foram apresentadas. Isso permite observar como o sujeito lida com o tempo em um momento de dificuldade.

O segundo aspecto que nos chama atenção é a também facilidade com que RM nomeia e explica a condição com que seu neto nasceu. É interessante notar como o sujeito

\footnotetext{
${ }^{16}$ No original, "In order to collect and analyze natural, dynamic and complex data, it is important to have the flexibility to adjust the methods of both data collection and analysis to fit the needs of the research at any specific time".
} 
explica com detalhes a natureza complexa da condição do neto. RM leva menos de um minuto para explicar do que se trata a condição utilizando léxico relevante e apropriado como "mielomeningoceli", "cóccix", "enervação", "cadeirante paralítico", "hidrocefalia" sem dificuldade. Podemos assumir que o fato de RM estar tão próxima à realidade do neto e de acompanhá-lo desde o nascimento, como relatou em outros momentos da entrevista, é significativo da importância, para RM, de saber o que é e como explicar essa condição. Isso sugere a importância de considerarmos as práticas sociais em que os sujeitos se encontram no momento de analisar suas escolhas lexicais. Nesse sentido, portanto, a maneira como os testes padrão investigam a relação entre palavras de baixa ou alta frequência e envelhecimento é colocada em cheque.

Os dois momentos em que RM parece apresentar uma certa dificuldade são resolvidos de maneira rápida. No primeiro caso, RM, ao citar o nome da condição do neto, corrige-se imediatamente, levando cerca de três segundos (9'47 até 9'50): "porque a minha filha do meio tem um filho que nasceu com mielo/ meni/ meningoceli”. Em um segundo momento, RM afirma não ter certeza se o neto foi operado no mesmo dia do nascimento ou no dia seguinte: "e no dia mesmo lá... no outro não me lembro bem...", mas parece não considerar essa informação, nesse momento, relevante para explicar que o neto foi operado logo que nasceu. Foram tantas as informações apresentadas em um curto espaço de tempo que o fato de não oferecer esse dado, em relação ao quadro apresentado, não deve ser entendido como um indício de uma real dificuldade - como observamos com sujeitos afásicos que podem levar horas para conseguir chegar à palavraalvo.

Essa característica - a facilidade para trazer informações novas e relevantes e descartar eventuais informações - aparece também nesse segundo dado que apresentamos. Nesse momento, RM conta à entrevistadora LM informações sobre o neto mais velho que está de mudança para a Itália.

Dado 2. Entrevista com RM em 17/06/2016 - Mudança para Itália

\begin{tabular}{|c|c|l|}
\hline Sigla & Tempo & Enunciado \\
\hline RM & $11: 26$ & $\begin{array}{l}\text { eu tenho 7 netos... é muito bom... o filho mais velho é dessa de Ribeirão que casou } \\
\text { casou... engravidou na faculdade... ela fez arquitetura tava lá em... onde que é... } \\
\text { Bauru? E aí ela ficou grávida e é uma criança... uma benção divina tá formado em } \\
\text { engenharia mecânica... se formou esse ano... vem almoçar domingo comigo porque } \\
\text { ele sempre foi um exemplo }\end{array}$ \\
\hline LM & & seu neto né? \\
\hline RM & & meu neto mais velho \\
\hline LM & & a tá \\
\hline RM & $12: 54$ & $\begin{array}{l}\text { e... como ele pediu licença essa semana pra ir lá pra Itália agora ele tá trabalhando } \\
\text { dobrado... mas ele vai é... ele só vai trabalhar por hora porque ele foi convidado } \\
\text { para ficar em Bolonha. }\end{array}$ \\
\hline LM & $13: 06$ & pra estudar? \\
\hline RM & $\mathbf{1 3}$ '14 & $\begin{array}{l}\text { pra fazer pesquisa no no laboratório da ai desses carros de corrida aí muito famosos } \\
\text { não lembro o nome }\end{array}$ \\
\hline LM & 13 '16 & Ferrari? \\
\hline RM & $13 ’ 17$ & Ferrari! \\
\hline
\end{tabular}

Neste Dado 2, notamos dois momentos em que EM parece ter dificuldade maior para chegar à palavra-alvo. No primeiro deles, o sujeito recorda-se, quase imediatamente, 
da cidade onde a filha estudou "tava lá em... onde que é... Bauru?", levando, novamente, cerca de três segundos. No segundo momento, EM quer contar à investigadora onde o neto irá trabalhar, na Itália. Ela informa a cidade, mas não consegue se lembrar do nome do laboratório onde ele vai trabalhar. No momento da busca, EM verbaliza essa dificuldade à entrevistadora, convidando-a, ainda que não diretamente, a ajudá-la a alcançar seu intuito discursivo, assim como vimos no trecho da obra de Calvino: "pra fazer pesquisa no no laboratório da ai desses carros de corrida aí muito famosos não lembro o nome".

Esse dado dá visibilidade à importância da mobilização dos conceitos Bakhtinianos de dialogia para nos ajudar a melhor compreender certos aspectos do fenômeno da WFD. Como mostra Faraco (2009, p. 65-66), as relações dialógicas são:

[...] relações de sentido que se estabelecem entre enunciados, tendo como referência o todo da interação verbal e não apenas o evento da interação face a face. Assim, quaisquer enunciados, se postos lado a lado no plano do sentido, "acabam por estabelecer uma relação dialógica" (p. 117). Mesmo enunciados separados um do outro no tempo e no espaço e que nada sabem um do outro, se confrontados no plano do sentido, revelarão relações dialógicas (p. 124). E isso em qualquer ponto do vasto universo da criação ideológica, do intercâmbio sociocultural. As relações dialógicas - diz Bakhtin no mesmo manuscrito (p. 124) - não podem ser reduzidas a relações de ordem lógica, linguística (no sentido estrito do termo), psicológica, mecânica ou natural. São relações de sentido de um tipo especial que se estabelecem entre enunciados ou mesmo no interior de enunciados.

O segundo sujeito, EL, nasceu no interior de São Paulo em 1939, tendo mudado para a região de Campinas em 1967. EL mostrou-se alegre e bem-humorada ao longo de toda a entrevista. Em muitos momentos disse não entender porque estaria sendo entrevistada já que, para ela, não haveria nada de interessante em sua vida. Aposentada e viúva, estudou somente a $1^{\mathrm{a}}$ série, e mora atualmente com um dos quatro filhos em Campinas.

Dado 3. Entrevista com EL em 24/05/2016 - Tem que ser tudo certinho

\begin{tabular}{|c|c|c|c|}
\hline Sigla & Tempo & Enunciado & Observações \\
\hline LM & $0: 39$ & a senhora nasceu aqui em Campinas? & \\
\hline$\overline{E L}$ & $0: 39$ & não... nasci em Garça & \\
\hline LM & & $\mathrm{a}:::$ & \\
\hline EL & $\begin{array}{c}0: 40- \\
0: 43\end{array}$ & $\begin{array}{l}\text { mas me criei em Tupã e me casei em Rinópolis e viuvei em } \\
\text { Campinas }\end{array}$ & \\
\hline LM & & & $\overline{\mathrm{ri}}$ \\
\hline$\overline{E L}$ & & mas é... eu sou rápida pra falar... & fala rindo \\
\hline LM & $0: 51$ & quando que a senhora mudou aqui pra Campinas? & \\
\hline$\overline{E L}$ & $0: 52$ & em 67 & \\
\hline LM & & $\mathrm{a}:::$ & \\
\hline$\overline{E L}$ & $\begin{array}{l}0: 54 \\
1: 00\end{array}$ & $\begin{array}{l}\text { foi no mês... eu viajei pra cá no mês de agosto e em primeiro de } \\
\text { agosto eu peguei o trem lá... que naquele tempo tinha trem... hoje } \\
\text { não tem mais... eu peguei o trem lá... }\end{array}$ & \\
\hline $\mathrm{LM}$ & $1: 07$ & lá... onde? em... & (continua) \\
\hline
\end{tabular}




\begin{tabular}{|c|c|l|l|}
\hline Sigla & Tempo & Enunciado & Observações \\
\hline EL & $\mathbf{1 : 0 8}$ & $\begin{array}{l}\text { Tupã... e daí a minha mudança veio despachada com... [1:14] } \\
\text { quantos quilos gente. ai eu esqueci os quilos... 300 quilos [1:19] } \\
\text { com máquina de costura e tudo... cama colchão tudo }\end{array}$ & \\
\hline LM & $1: 39$ & $\begin{array}{l}\text { uau! } \\
\text { tinha uma mala que veio lá os presentes que eu ganhei no } \\
\text { casamento... eu fiquei 40 anos e ainda tenho louça que eu ganhei no } \\
\text { casamento! eu casei em... 59 }\end{array}$ & \\
\hline EL & & ahan... & \\
\hline LM & $1: 41$ & eu me casei 31 do 1 de 59 e eu enviuvei 31 do 1 de 99 [1:48] & \\
\hline EL & nossa... & $\begin{array}{c}\text { e ri ao final do } \\
\text { turno }\end{array}$ \\
\hline LM & & tudo... certinho... comigo tem que ser tudo certinho... & \\
\hline EL & &
\end{tabular}

Notamos no Dado 3, assim como nos dados anteriores, como EL apresenta informações relevantes de maneira rápida. Em apenas três segundos ('0:40 até '0:43), EL nomeia três cidades que marcaram sua vida pelos acontecimentos: onde foi criada (Tupã), onde se casou (Rinópolis) e onde perdeu o marido (Campinas). As informações fornecidas foram tão diretas que a investigadora riu e EL não perdeu a oportunidade de explicar "eu sou rápida para falar". Em seguida, EL informa quando se mudou para Campinas, fornecendo detalhes precisos, em apenas seis segundos ('0:54 até 1 '): “foi no mês... eu viajei pra cá no mês de agosto e em primeiro de agosto eu peguei o trem lá...". De maneira semelhante, EL informa, ao longo de sete segundos (' $1: 41$ até '1:48) a data de casamento e de falecimento do marido: "eu me casei 31 do 1 de 59 e eu enviuvei 31 do 1 de 99”.

Vale a pena notar que não se trata de fornecer informações que não sejam relevantes. Pelo contrário, observamos como EL aprecia informações precisas: "comigo tem que ser tudo certinho". Isso não revela apenas a capacidade desse sujeito de, quando necessário, acessar informações relevantes para atingir seu intuito discursivo, mas aspectos da personalidade de EL que não devem ser confundidos, como procuramos mostrar ao longo desta reflexão, ao fato de ela ser idosa. A essencialização de determinadas características (de detalhes parciais, como vimos anteriormente) sustenta estereótipos de "rigidez", tantas vezes associados ao envelhecimento. O que notamos, ao longo da entrevista, contudo, é uma personalidade forte de quem saiu da região onde nasceu "por estar cansada de ser empregada dos irmãos" para trabalhar em Campinas na roça, ser empregada doméstica de consultório odontológico e, hoje, ter dois apartamentos na região de classe média de Campinas. Não se trata de valorizar, apenas, as conquistas de quem conseguiu, apesar de tantas dificuldades ${ }^{17}$, criar seus filhos, mas de ressaltar a relevância que essa informação pode ter para a compreensão de aspectos linguísticos de idosos.

Também como EM, EL mostra um momento de maior dificuldade ao informar quantos quilos ela trouxe, em sua bagagem, quando se mudou para Campinas. Também como EM, EL verbaliza essa dificuldade "quantos quilos gente? ai eu esqueci os

\footnotetext{
17 Em diversos momentos EL relatou a dificuldade de trabalhar para determinadas "patroas", com a instabilidade financeira dela e do marido que, ao longo de quase toda a vida, vendeu comida pelas ruas de Campinas.
} 
quilos...", mas logo se lembra "300 quilos". EL leva em torno de cinco segundos ("1:14 até '1:19) para chegar à palavra-alvo e assim com o EM, EL, ao verbalizar, convida a entrevistadora a ajudá-la, mostrando domínio de uma estratégia linguístico-cognitiva para ganhar tempo enquanto buscam a palavra-alvo.

A análise dos dados mostra, ainda que de maneira diferente do que vimos no Dado 2 com EM, o caráter dialógico da busca pela palavra-alvo, no momento da dificuldade, uma vez que, como afirma Volóchinov (2017, p. 184), um "todo enunciado [...] responde a algo e orienta-se para uma resposta. Ele é apenas um elo na cadeia ininterrupta de discursos verbais". Em outras palavras, estamos, sempre, respondendo a outros enunciados, ainda que não imediatos, ainda que internos ("para si"), como o "quantos quilos gente" a que EL se refere, uma vez que o "gente" não se refere aos interlocutores presentes no momento da entrevista.

\section{Considerações finais}

A partir das reflexões desenvolvidas neste artigo, que é parte de uma pesquisa mais ampla em andamento, procuramos mostrar como a perspectiva adotada pela Neurolinguística de orientação Enunciativo-Discursiva possibilita olhar para fenômenos associados ao envelhecimento, como a Dificuldade para Encontrar Palavras, de maneira a refletir criticamente sobre eles, o que, por sua vez, nos ajuda a construir uma imagem mais completa desse quadro que é envelhecer.

Sabemos que os estudos sobre linguagem e envelhecimento precisam ser melhor investigados, mas como no romance de Calvino, o pesquisador, ao compartilhar a perspectiva aqui adotada, é como o Leitor que deixa de assumir uma postura passiva e, ao sair em busca do fim romance, depara-se com diversas outras narrativas pelas quais também passa a se interessar e, nesse processo de descoberta, torna-se parte fundamental da própria resposta buscada. É, portanto, nesse percurso de aprendizagem, descobertas e respostas (muitas vezes parciais) que conseguimos avançar na prática do fazer pesquisa.

\section{REFERÊNCIAS}

AMOSSY, R.; HERSCHBERG-PIERROT, A. Estereotipos y clichés. Buenos Aires: Eudeba, 2001. A PIADA do povo brasileiro. I miei appunti. Disponível em: $<$ https://mieiappunti.wordpress.com/2010/02/03/povo-brasileiro/>. Acesso em: 28 jul. 2017.

ARBUCKLE, T.; GOLD, D. Aging, Inhibition, and Verbosity. Journal of Gerontology: Psychological Sciences, Waltham, v. 48, n. 5, p. 225-232, 1993.

BAKHTIN, M. Os gêneros do discurso. Estética da Criação Verbal. São Paulo: Martins Fontes, 2003.

BRANDÃO, L. Produção da linguagem e envelhecimento. In: PARENTE, M. A. M. et al. Cognição e envelhecimento. Porto Alegre: Artmed Editora S.A., 2006.

BRANDÃO, L.; PARENTE, M. A. DE M. Os estudos de linguagem do idoso neste último século. Estudos Interdisciplinares sobre o Envelhecimento, Porto Alegre, v. 3, p. 37-53, 2001. 
BURKE, D. M. Language, Aging, and Inhibitory Deficits: evaluation of a theory. Journal of Gerontology: Psychological Sciences, v. 52B, n. 6, p. 254-264, 1997.

BURKE, D. M.; SHAFTO, M. A. Aging and language production. Curr Dirr Psychol Sci, v. 13, n. 1, p 21-24, 2004.

CALVINO, I. Se um viajante numa noite de inverno. São Paulo: Companhia das Letras, 2011.

CARMELINO, A. C.; POSSENTI, S. O que dizem do Brasil as piadas? Linguagem em (Dis)curso-LemD, Tubarão, v. 15, n. 3, p. 415-430, set./dez. 2015.

COUDRY, M. I. Diário de Narciso: discurso e afasia. São Paulo: Martins Fontes, 1988 [1986].

DAMICO, J.; SIMMONS-MACKIE N.; OELSCHLAEGER, M.; ELMAN, R.; ARMSTRONG, E. Qualitative methods in aphasia research: basic issues, Aphasiology, 13, p. 651-665, 1999.

DELL, G. S. A spreading activation theory of retrieval in language production. Psychological Review, 93, p. 283-321, 1986.

FARACO, C. A. Linguagem e diálogos: as idéias linguísticas do círculo de Bakhtin. São Paulo: Parábola Editora, 2009.

FRANCHI, C. Hipóteses para uma teoria funcional da linguagem. 1975. 259 f. Tese (Doutorado em Linguística) - Instituto de Filosofia e Ciências Humanas, Universidade Estadual de Campinas, Campinas, 1975.

FUGIWARA, R. E.; NOVAES-PINTO, R. C. Avaliação de compreensão nas afasias. Estudos Linguísticos, São Paulo, 42 (2), p. 903-915, 2013.

GARFINKEL, H. Studies in ethnomethology. Englewood Cliffs, NJ: Prentice Hall, 1967.

GARRETT, M. F. The Analysis of Sentence Production. In: BOWER, G. (Org.). The Psychology of Learning and Motivation, 9, New York: Academic Press. 1975.

GERALDI, W. Linguagem, interação e ensino. 1990. 334 f. Tese (Doutorado em Linguística) - Instituto de Estudos da Linguagem, Universidade Estadual de Campinas, Campinas, 1990.

GÓES, M. C. R. A abordagem microgenética na matriz histórico-cultural. Caderno Cedes, v. 50, p. 9-25, 2000.

GOODWIN, C. Conversational organization: interaction between speakers and hearers. New York: Academic Press, 1981.

HÉBERT, R. A revolução do envelhecimento. Ciência \& Saúde Coletiva, v. 20, n. 12, 2015.

HERITAGE, J. Garfinkel and ethnomethodology. Cambridge: Polity Press, 1984.

KOTIK-FRIEDGUT, F. Development of the Lurian Approach: a cultural neurolinguistics perspective. Neuropsychology Review, v. 16, n. 1, p. 43-52, 2006.

LOURENÇO, R.; MASSI, G. Linguagem e Velhice: considerações acerca do papel da escrita no processo de envelhecimento. Curitiba: Juruá Editora, 2011. 
LURIA, A. R. Cognitive Development: its cultural and social foundations. Cambridge, Massachusetts. London: Harvard University, 1990.

. Curso de psicologia geral. Rio de Janeiro: Brasileira, 1991.

MARCUSCHI, L. A. Introdução. In: PRETI, D. A linguagem dos idosos: um estudo de análise da conversação. São Paulo: Contexto, 1991.

MAZUCHELLI, L. P. O efeito de práticas sociais com leitura e escrita no caso de uma afasia progressiva: (re)encontros. 2012. 145 f. Dissertação (Mestrado em Linguística) Instituto de Estudos da Linguagem, Universidade Estadual de Campinas, Campinas, 2012.

MINAYO, M. C. S.; GUALHANO, L. Cuidados frente à revolução da longevidade. Ciência \& Saúde Coletiva, Rio de Janeiro, v. 19, n. 8, Press Release, 2014.

NERI, A. Envelhecer num país de jovens. Campinas: Editora da UNICAMP, 1991.

NOVAES-PINTO, R. C. Preconceito Lingüístico e Exclusão Social na Normalidade e nas chamadas Patologias de Linguagem. Avesso do Avesso, v. 6, p. 8-36, 2008.

Avaliação de compreensão de linguagem: análise de resultados obtidos em baterias de testes neuropsicológicos versus análise discursiva de episódios dialógicos. Veredas, UFJF: Impresso, v. 1, p. 2-12, 2007.

PRETI, D. A linguagem dos idosos: um estudo de análise da conversação. São Paulo: Contexto, 1991.

RYAN, E.; LAURIE, S. Evaluations of Older and Younger Adult Speakers. Psychology and Aging, Claremont, v. 5, p. 514-519, 1990.

SALTHOUSE, T. The Role of Representativeness in Age Differences in Analogical Reasoning. Psychology and Aging, Claremont, v. 2, p. 357-362, 1987.

STINE, E.; WINGFIELD, A.; POON, L. Speech Comprehension and Memory Through Adulthood. Everyday Cogn in Adult and Late Life. p. 195-229. New York: Cambridge, 1989.

VAN DIJK, T. Contextual knowledge management in discourse production. Conference Society for Text and Discourse, Madrid, 2003.

VOLÓCHINOV, V. Marxismo e Filosofia da Linguagem. São Paulo: Editora 34, 2017.

VYGOTSKY, L. S. A construção do pensamento e da linguagem. São Paulo: Martins Fontes, 2010 [1984].

Recebido em: 30/08/2016

Aprovado em: 29/11/2016 